\title{
Furan Resin as Potential Substitute for Phenol- formaldehyde Resin in Plywood Manufacturing
}

Anca Maria Varodi, ${ }^{*}$ Emanuela Beldean, and Maria Cristina Timar

Replacement of phenol-formaldehyde with a mixed furan resin is considered in this work as a means to improving plywood properties made with urea-formaldehyde-based adhesive currently made with an addition of phenol-formaldehyde resin. Previous research showed that the furan resins can improve water resistance and can provide long stability for the glue line. Plywood was manufactured with modified adhesives and characterized in comparison with a reference product. Thickness, physical properties (moisture content, density, and total water absorption), mechanical properties (shearing strength, bending strength, and elasticity modulus in bending), and formaldehyde emission were determined according to standardized methods. The results indicated that the addition of furan resin enhanced the water resistance by $43 \%$ and formaldehyde emission is according to E1 class. Also, the mechanical properties were improved; the shear strength for the adhesive composition with furan resin was increased by 14 to $30 \%$ compared with the reference product, depending on the testing conditions.

Keywords: Bio-resources; Adhesives; Plywood; Water resistance; Mechanical properties

Contact information: Transilvania University of Brasov, Faculty of Wood Engineering, Universitatii Str. 1, 500036 Brasov, Romania; *Corresponding author: anca.varodi@unitbv.ro

\section{INTRODUCTION}

Urea-formaldehyde (UF), phenol-formaldehyde (PF), and other formaldehydebased resins are the most used adhesives for the gluing of various wooden products (Pizzi and Mittal 2003; Zhang et al. 2014). As the urea-formaldehyde resins are the most widely employed adhesives for wood products, improvement of their properties is still an important research topic. For instance, recent studies refer to employment of inorganic nanoparticles for reducing water absorption (Djiporovic-Momcilovic et al. 2018). In the same context, phenol-formaldehyde resins are employed as additives in ureaformaldehyde adhesive mixtures to improve their water resistance in the production of plywood.

The development of eco-friendly binders made from natural bio-resources with improved mechanical properties and water resistance is of high interest for the woodbased industry (Pizzi 2016; Hemmilä et al. 2017). The use of tannin as bio-adhesive shows an increase of water resistance, but economically speaking the industrial usage of this kind of adhesive is not profitable (Hemmilä et al. 2017). A recent study regarding soy protein adhesives pointed out that this bioresource is suitable for gluing plywood for interior use (Hao and Fan 2018).

In the research presented in this paper, furan resins from furfural obtained by processing the agricultural wastes were investigated. This renewable bioresource is a subject of interest due to the potential environmental impact of wood gluing processes 
(Gosselink et al. 2011; Dong et al. 2014; Herold et al. 2014; Rivero et al. 2014). Dongre et al. (2015) proposed lignin-furfural resins as an alternative for phenol-formaldehyde resins. His study shows the capacity of furan resin to maintain the desired mechanical properties of wood panels and the possibility to lower the costs.

Historically speaking, Ponomarev (1960) was the first researcher who indicated that furan resins show good adhesion to wood but insufficient adhesion to metals. Different studies regarding the use of furan resins and furan-formaldehyde resins have shown an improvement in water resistance for particleboard and plywood (Schultz 1990; Kim et al. 1998; Schneider 2002; NPCS 2007; Abdullah and Pizzi 2013). Other studies suggested that the use of mixed furan resin condensed with different reagents will achieve improvements in wood-based products, such as particleboard, fibreboard, and OSB (Luckeneder et al. 2016; Pizzi 2016).

Zhang (2014) showed that plywood made with adhesives based on modified ureaformaldehyde resin, with furfural in the synthesis phase, revealed improved mechanical properties.

The furan formaldehyde resin was proposed in this work as a potential substitute for phenol-formaldehyde resin in UF-PF mixtures for plywood gluing, obtained by the polycondensation of furfuryl alcohol with formaldehyde.

Previous studies demonstrated that the furan resin, which cross-linked at $20{ }^{\circ} \mathrm{C}$, can be used with good results as an adhesive for glue laminated timber (Zeleniuc et al. 2010) and can be rated as a Type 1 structural adhesive with good water resistance (Varodi et al. 2013).

The water absorption, the mechanical properties (i.e., shear strength and bending strength modulus of elasticity), and the free formaldehyde emission of plywood manufactured with three types of adhesives were presented in this study. Based on the results, the plywood was further classified according to SR EN 636 (2004).

\section{EXPERIMENTAL}

\section{Materials and Methods}

Plywood made with seven layers of veneers was manufactured in two pilot series at S. C. Silva Carpat S. A., Braşov, Romania. The S.C. Silva Carpat S.A. is an economic agent specialized in producing elastic laminated veneer structures and beech (Fagus sylvatica) plywood for indoor applications. Each plywood panel was made from seven technical veneers of beech wood: two veneers as surface layers with a thickness of 1.00 $\mathrm{mm}$ and five veneers with a thickness of $1.20 \mathrm{~mm}$ for the middle layers. All veneers used were from the current production of the mentioned economic agent with a moisture content of $12 \%$ and the dimensions of $2100 \times 1400 \mathrm{~mm}$.

\section{Adhesive composition}

The characteristics for all three types of polycondensation resins employed in the mixture of the used adhesives are presented in Table 1 (the physical-chemical characteristics data provided by the producer S. C. Viromet SA, Victoria City, Romania). The data in this table show that the densities and the solid contents were nearly the same for all three resins. The most apparent difference was observed at free formaldehyde content data. The value registered for the URLEIT FC2 furan resin was much higher than the UF and PF resins employed. 
Table 1. Physical and Chemical Characteristics of the Employed Resins

\begin{tabular}{|c|c|c|c|c|}
\hline \multirow{2}{*}{\multicolumn{2}{|c|}{$\begin{array}{l}\text { Physical and Chemical } \\
\text { Characteristics }\end{array}$}} & \multicolumn{3}{|c|}{ Resins Name } \\
\hline & & $\begin{array}{l}\text { UF Resin } \\
\text { Adhesive G } \\
\text { (AG) }\end{array}$ & $\begin{array}{c}\text { PF Resin } \\
\text { STERON (F4) }\end{array}$ & $\begin{array}{c}\text { Furan Resin } \\
\text { Mixed with Alcohol } \\
\text { Furfurylic } \\
\text { (URELIT FC2) }\end{array}$ \\
\hline \multicolumn{2}{|c|}{ Aspect } & $\begin{array}{l}\text { Viscous liquid } \\
\text { homogeneous }\end{array}$ & $\begin{array}{l}\text { Homogeneous } \\
\text { liquid }\end{array}$ & $\begin{array}{l}\text { Viscous liquid } \\
\text { homogeneous }\end{array}$ \\
\hline \multicolumn{2}{|c|}{ Color } & White & Red-brown & Yellow-white \\
\hline \multicolumn{2}{|c|}{ Density at $20^{\circ} \mathrm{C}\left(\mathrm{g} / \mathrm{cm}^{3}\right)$} & 1.280 to 1.295 & $1.170 \pm 0.030$ & $1.275 \pm 0.015$ \\
\hline \multicolumn{2}{|c|}{$\begin{array}{c}\text { Dynamic viscosity at } 20^{\circ} \mathrm{C} \\
(\mathrm{mPa} / \mathrm{s})\end{array}$} & 800 to 1200 & 400 to 2000 & 700 to 1250 \\
\hline \multicolumn{2}{|c|}{ Solid content (\%) } & $66 \pm 1$ & $50 \pm 2$ & $68 \pm 2$ \\
\hline \multicolumn{2}{|c|}{$\begin{array}{l}\text { Free formaldehyde content } \\
(\%) \max \end{array}$} & 0.06 to 0.15 & 1.2 & 3.5 \\
\hline \multicolumn{2}{|c|}{$\mathrm{pH}$} & 8.8 & 8 to 10 & 6.5 to 7.5 \\
\hline \multicolumn{2}{|c|}{ Free phenol content (\%) max } & - & 1,0 & - \\
\hline \multicolumn{2}{|c|}{ Water miscibility (\%) min } & $1: 1$ to $1: 2$ & $1: 1$ to $1: 3$ & - \\
\hline \multirow{2}{*}{$\begin{array}{l}\text { Reactivity (s) } \\
\text { max }\end{array}$} & $100^{\circ} \mathrm{C}$ & 50 to 65 & - & - \\
\hline & $160^{\circ} \mathrm{C}$ & - & 180 & - \\
\hline
\end{tabular}

Three adhesives compositions based on the above presented resins were prepared and tested in order to improve the plywood properties. An adhesive composition based on UF resin, with $3.33 \%$ of PF resin, coded as AG-F4 was used as reference adhesive mixture. An adhesive composition based on UF resin with $3.33 \%$ of furan resin and mixed with URELIT FC2 was coded as AG-FC2/1. The last adhesive composition was also based on UF resin but with $6.66 \%$ furan resin $\mathrm{FC}_{2}$, coded as AG-FC2/2. The compositions for all adhesives used in this pilot experiment are summarized in Table 2.

Table 2. Adhesives Composition

\begin{tabular}{|c|c|c|c|c|}
\hline \multirow{2}{*}{ Adhesives Composition } & \multirow{2}{*}{$\begin{array}{c}\text { Units of } \\
\text { Measurement }\end{array}$} & \multicolumn{3}{|c|}{$\begin{array}{c}\text { Indicatives of Adhesive Compositions } \\
\text { (Resin Type/Catalyst Type) }\end{array}$} \\
\cline { 3 - 5 } & & $\mathrm{AG}$-F4 & AG-FC2/1 & AG-FC2/2 \\
\hline UF resin Adhesive G (AG) & $\mathrm{kg}$ & 60 & 60 & 60 \\
\hline PF resin STERON (F4) & $\mathrm{kg}$ & 2 & - & - \\
\hline $\begin{array}{c}\text { Furan Resin Mixed with } \\
\text { Alcohol furfurylic type URELIT } \\
\text { FC2 (FC2) }\end{array}$ & $\mathrm{kg}$ & - & 2 & 4 \\
\hline $\begin{array}{c}\text { Solid ammonium chloride } \\
\text { (NH4CI) }\end{array}$ & $\mathrm{kg}$ & 0.7 & 0.7 & 0.7 \\
\hline Rye flour & $\mathrm{kg}$ & 8 & 8 & 8 \\
\hline Water & $\mathrm{I}$ & 5 & 5 & 5 \\
\hline
\end{tabular}

As filler-extender, a constant amount of $12.33 \%$ rye flour (the mass percentage was reported for the UF resin) was employed. The catalyst used, was the same amount of solid ammonium chloride, $1.17 \%$ (mass percentage reported to the UF resin) for all adhesive compositions. This type of catalyst is currently used in production and it is in accordance with other studies that have involved furan resins (Zhang et al. 2014).

The physical-chemical properties of the used adhesives compositions are presented in Table 3. 
Table 3. Physical-Chemical Properties of Adhesives Compositions

\begin{tabular}{|c|c|c|c|c|}
\hline $\begin{array}{c}\text { Physical-chemical } \\
\text { Properties of Adhesive } \\
\text { Compositions }\end{array}$ & \multirow{2}{*}{$\begin{array}{c}\text { Units of } \\
\text { Measurement }\end{array}$} & \multicolumn{3}{|c|}{$\begin{array}{c}\text { Indicatives of Adhesive Compositions } \\
\text { (Resin Type/Catalyst Type) }\end{array}$} \\
\cline { 3 - 5 } & & AG-F4 & AG-FC2/1 & AG-FC2/2 \\
\hline Initial pH & - & 6.0 & 6.0 & 6.0 \\
\hline Final pH & - & 5.0 & 4.0 & 4.0 \\
\hline $\begin{array}{c}\text { Flow time through FORD } \\
\text { cup Ø8 mm, at } 20^{\circ} \mathrm{C}\end{array}$ & $\mathrm{s}$ & 36 & 28 & 30 \\
\hline Gel time $\left(t_{\mathrm{g}}\right)$ at $100^{\circ} \mathrm{C}$ & $\mathrm{s}$ & 90 & 78 & 62 \\
\hline Curing time $\left(t_{\mathrm{s}}\right)$ at $20^{\circ} \mathrm{C}$ & $\mathrm{s}$ & - & 182 & 178 \\
\hline Viability at $20^{\circ} \mathrm{C}$ & $\mathrm{h}$ & 4 & 4 & 4 \\
\hline
\end{tabular}

The data presented in Table 3 show that the two adhesive compositions modified with furan resin URELIT FC2 had a lower final $\mathrm{pH}$ after gel formation, compared to the reference adhesives. The viscosity, expressed as flowing time through a standard flow viscosity cup FORD type, with a nozzle diameter of $8 \mathrm{~mm}$ at $20{ }^{\circ} \mathrm{C}$, decreased by approximately $16 \%$ to $20 \%$ compared to the reference.

The gelling time at $100{ }^{\circ} \mathrm{C}$ of the two adhesive modified compositions was also smaller. For adhesive composition coded AG-FC2/1, the gelling time was $78 \mathrm{~s}$ and for AG-FC2/2 the gelling time was $62 \mathrm{~s}$. The difference between the reference and tested furan resin was $12 \mathrm{~s}$ for AG-FC2/1 and $28 \mathrm{~s}$ for AG-FC2/2. The shorter gelling time can be correlated with the more acidic $\mathrm{pH}$. With increasing of the percent of furan resin the gelling time decreased, which was in accordance with Abdullah and Pizzi (2013) who developed tannin-furfuryl alcohol adhesives for wood panels.

The curing time was considered as the time between gel phases until cured resin is finished. Zhang (2014) reported the same effect of increasing the curing time of adhesives based on some urea-formaldehyde furfural co-condensed resin using the same catalyst. In the same study, the researchers indicated that if another type of catalyst was used, the reaction can be sped up.

The adhesive compositions were applied with a roller gluing machine (Karl Tränklein GmbH, Schönaich, Germany), and the pressing of veneer packages was achieved in a flat press SIWO type (SIWO GmbH, Hamburg Germany). The gluing parameters used on the industrial scale were the same for all cases when the pressing temperature was $110{ }^{\circ} \mathrm{C}$, specific pressure $1.7 \mathrm{~N} / \mathrm{mm}^{2}$, at a pressing time of $9 \mathrm{~min}$. The adhesive application rate ranged from $130 \mathrm{~g} / \mathrm{m}^{2}$ to $150 \mathrm{~g} / \mathrm{m}^{2}$ and was applied on a single side of veneers.

After the flat press, the plywood was conditioned for 7 days and sized to a final format of $2100 \mathrm{~mm} \times 1300 \mathrm{~mm}$. Six plywood sheets were manufactured with each of the three adhesive mixtures.

The costs of $1 \mathrm{~m}^{3}$ of glued plywood, for an average value of $150 \mathrm{~g} / \mathrm{m}^{2}$ as adhesive consumptions were slightly reduced for the adhesive composition mixed with the same amount of furan resin (AG-FC2/1) compared with reference (AG-F4). However, by increasing the quantity of furan resin (AG-FC2/2), the cost will also increase, and the properties will be improved as well (water resistance and mechanical properties). 


\section{FTIR investigation of used adhesives}

FTIR spectra were recorded using an ALPHA Bruker spectrometer equipped with ATR (attenuated total reflection) module in the range 4000 to $400 \mathrm{~cm}^{-1}$ at a resolution of $4 \mathrm{~cm}^{-1}$ and 24 scans/ spectrum. The spectra were registered for the cured adhesives (reference and modified adhesive AG-FC2/2). Spectra from three randomly chosen measuring areas were registered for each sample and further processed for baseline correction and smoothing. An average spectrum of the three individually recorded spectra was computed. Average spectra were further normalised (Max-Min normalisation) and compared. Assignment of characteristic absorption bands was based on literature references. The OPUS software was employed for all spectra processing and calculations.

\section{Physical-mechanical characteristics}

Before testing the plywood panels, they were conditioned for $72 \mathrm{~h}$ at $20{ }^{\circ} \mathrm{C} \pm 2{ }^{\circ} \mathrm{C}$ and with a relative humidity of $65 \% \pm 5 \%$.

The determination of the plywood thickness was made in accordance with SR EN 3241 (1993), the moisture content was performed in accordance with SR EN 322 (1996), and the density was determined in accordance with SR EN 323 (1996).

Although the total water absorption is not a compulsory property for interior plywood, it was considered useful to highlight the effect of furan resin addition on the water resistance of the glued products. Thus, test samples of plywood with dimensions of $100 \mathrm{~mm} \times 100 \mathrm{~mm} \times 7 \mathrm{~mm}$ were immersed for $24 \mathrm{~h}$ in water at $20{ }^{\circ} \mathrm{C} \pm 1{ }^{\circ} \mathrm{C}$ (STAS 10913 - 1977). Eq. 1,

The total water absorption is symbolized by $A_{\mathrm{t}}(\%)$ and was calculated by using

$$
A_{t}(\%)=\frac{\left(m_{2}-m_{1}\right)}{m_{1}} \times 100
$$

where $A_{\mathrm{t}}$ is the total water absorption of the plywood (\%), $m_{1}$ is the weight of the conditioned samples before immersion in water $(\mathrm{g})$, and $m_{2}$ is the weight of the samples after immersion in water for $24 \mathrm{~h}$ at $20^{\circ} \mathrm{C}(\mathrm{g})$.

The following standards were used to determine the mechanical properties: SR EN 3141 (2005) for shear strength, and SR EN 310 (1996) for the bending strength and modulus of elasticity in bending (MOE). A universal testing machine Zwick Roell Z 250 (Zwick GmbH \&Co.KG, Ulm, Germany) with a testing rate of $2 \mathrm{~mm} / \mathrm{min}$ was used. The percentage of wood failure in the bonding area was measured in accordance with SR EN 3141 (2005).

The determination of the shear strength was made on three types of samples, as presented in Fig. 1. These samples were coded as Long 1, Long 2, and Long 3. Ten replicates were tested for each type of sample, representing a total of 30 samples/types of plywood.

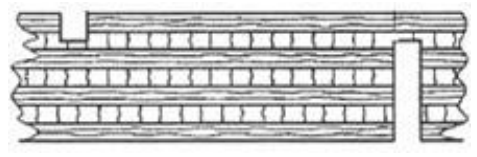

Long 1

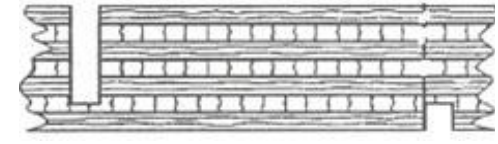

Long 2

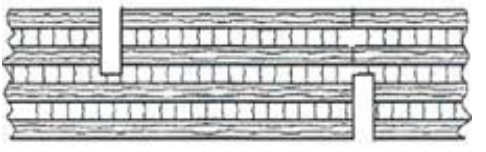

Long 3

Fig. 1. The schematic representation of the three types of samples for shear strength testing, according to SR EN 314-1 (2005) 
The formaldehyde emissions of the plywood boards were determined by the gas analysis method. A Timber test equipment by Stephen Young and Associates (New Plymouth City, New Zealand) was used in accordance with SR EN 7172 (1995).

All of the obtained experimental data were statistically analyzed with a one-way ANOVA test to find out the significant difference between the reference sample and tested samples. The analyses of variance were performed with Excel 2010 (Microsoft Corporation, Microsoft Office 2010, Albuquerque, NM, USA).

\section{RESULTS AND DISCUSSION}

\section{FTIR spectra}

The FTIR features of the cured adhesives compositions, with common and differentiating aspects, are presented in Fig. 2.

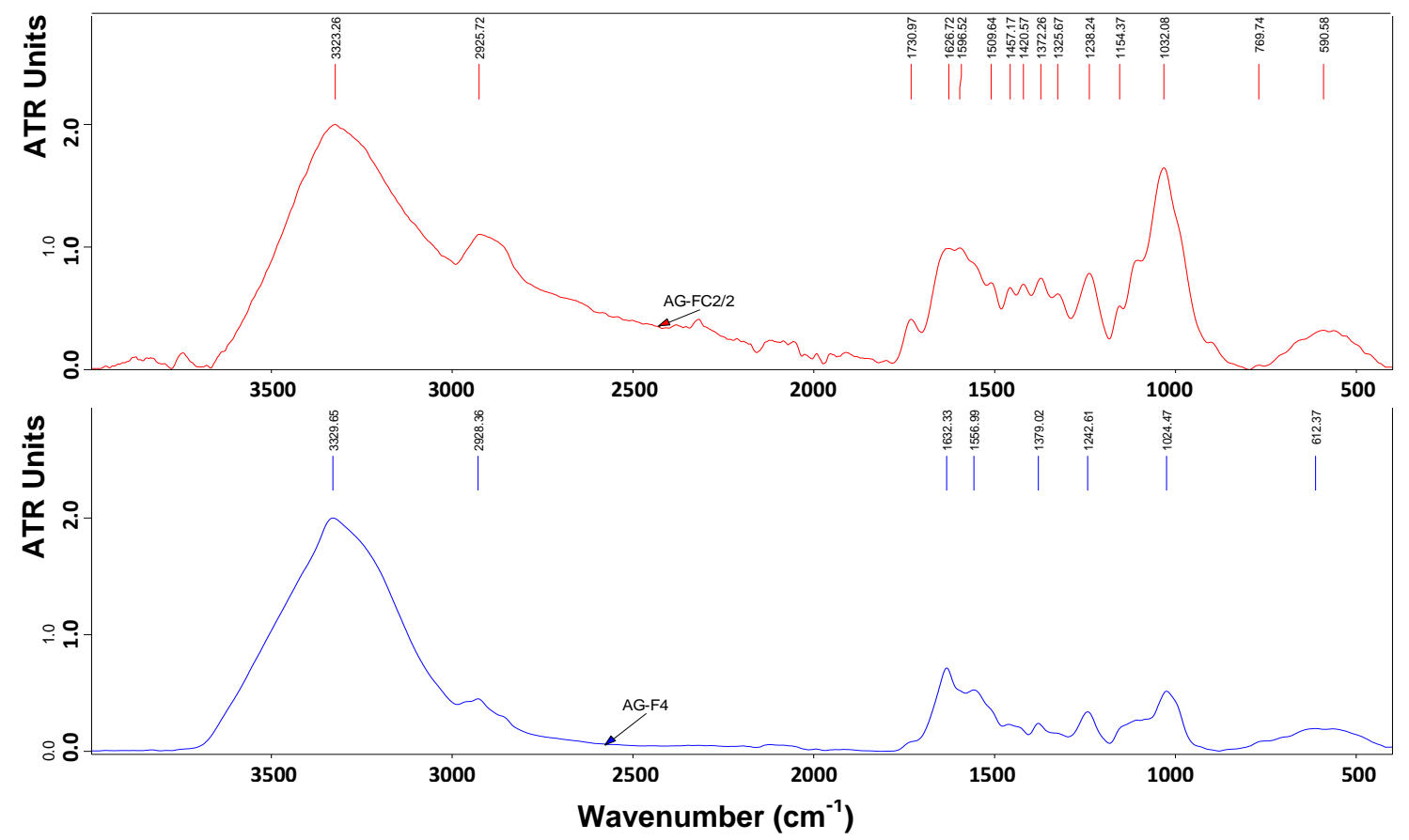

Fig. 2. The FTIR spectra registered for the cured adhesives compositions: reference (AG-F4) and the mixture composition with furan resin (AG-FC2/2)

Absorbance in the range 3000 to $3600 \mathrm{~cm}^{-1}$ can be associated with both $\mathrm{O}-\mathrm{H}$ and $\mathrm{N}-\mathrm{H}$ bonds; therefore the band is common and cannot provide much information. Absorption at $2928 \mathrm{~cm}^{-1}$ can be assigned to $\mathrm{C}-\mathrm{H}$ vibration in methylene groups. This band is larger for the cured adhesives modified with furan resins, which is expected, as methylene bridges are characteristic structural features for these condensation resole resins and more methylene bridges are formed by curing, which is consistent with proposed structures in the literature (e.g. Zhang et al. 2014). The absorption bands at $1632 \mathrm{~cm}^{-1}$ and $1597 \mathrm{~cm}^{-1}$, common to both spectra, are assignable to carbonyl bonds in amides (amide I) and N-H bonds (amide II). According to Tian et al. 2009, the presence of furan rings can be associated with the characteristic absorption bands at $\sim 1509 \mathrm{~cm}^{-1}$ ( $\mathrm{C}=\mathrm{C}$ in furan ring), $1154 \mathrm{~cm}^{-1}$ (C-O in furan ring), and $1032 \mathrm{~cm}^{-1}$ (furan ring vibration). These bands were present only in the FTIR spectra of the adhesives mixtures modified 
with furan resins. The absorption band at $1730 \mathrm{~cm}^{-1}$, assignable to saturated unconjugated carbonyls, was present only in the spectrum of the adhesive mixture modified with furan resins.

\section{Physical Characteristics}

The physical characteristics and the formaldehyde emission of the experimental beech plywood with seven layers of veneer are presented in Table 4.

Table 4. Thickness, Physical Properties, and Formaldehyde Emission of Plywood

\begin{tabular}{|c|c|c|c|c|c|}
\hline $\begin{array}{c}\text { Indicative of } \\
\text { Adhesives } \\
\text { Composition }\end{array}$ & $\begin{array}{c}\text { Plywood } \\
\text { Thickness } \\
(\mathrm{mm})\end{array}$ & $\begin{array}{c}\text { Moisture } \\
\text { Content } \\
(\%)\end{array}$ & $\begin{array}{c}\text { Density } \\
\left(\mathrm{g} / \mathrm{cm}^{3}\right)\end{array}$ & $\begin{array}{c}\text { Total Water } \\
\text { Absorption }(\%)\end{array}$ & $\begin{array}{c}\text { Formaldehyde } \\
\text { Emission }\left(\mathrm{mg} / \mathrm{m}^{2} \mathrm{~h}\right)\end{array}$ \\
\hline $\begin{array}{c}\mathrm{AG}- \\
\mathrm{F} 4 / \mathrm{NH}_{4} \mathrm{Cls}\end{array}$ & 7.13 & 6.55 & 0.784 & 30.84 & 3.01 \\
\hline $\begin{array}{c}\mathrm{AG}- \\
\mathrm{FC} 2 / 1 / \mathrm{NH}_{4} \mathrm{Cls}\end{array}$ & 7.38 & 6.31 & 0.715 & 26.70 & 3.32 \\
\hline $\begin{array}{c}\mathrm{AG}- \\
\mathrm{FC} / 2 / \mathrm{NH}_{4} \mathrm{Cls}\end{array}$ & 7.29 & 6.21 & 0.773 & 17.60 & 3.40 \\
\hline
\end{tabular}

The experimental data from Table 4 indicate that the plywood glued with modified resin had approximately the same moisture content and density as the reference, while the total water absorption was reduced. The water absorption decreased as furan resin amount increased. In this case, the water absorption was lower, approximately $43 \%$ compared to the plywood manufactured with the reference adhesive mixture.

Esmaeili et al. (2017) reported the same effect of reducing the water absorption and the thickness swelling for wood-based panels made with adhesives based on a ureahydroxymethyl furfural-formaldehyde resin. Although the formaldehyde emission slightly increased for the plywood manufactured with the adhesive mixture modified with furan resin, it still remained in the E1 class of emission.

\section{Mechanical Properties}

Shear strength

The results of shear strength tests were expressed as an average of 10 replicates. The graphs shown in Fig. 3 present the mean shear strength and standard deviation determined for Long 1 (Fig. 3a), Long 2 (Fig. 3b), and Long 3 (Fig. 3c) samples. Each adhesives composition was tested in the dry state, after $24 \mathrm{~h}$ immersion in water at $20^{\circ} \mathrm{C}$ temperature, and after $3 \mathrm{~h}$ immersion in water at $67{ }^{\circ} \mathrm{C}$ temperature.

The shear strength for the plywood made with modified adhesive was higher regardless of the testing conditions. When the addition of furan resin was increased, the shear strength also increased, which demonstrated the positive effect of furan resin on plywood properties. The samples Long 1 and Long 2 exhibited nearly the same type of milling process. The shape of Long 3 samples was specialized for the bonding strength of the inner plywood layers. The values of Long 3 were higher than the Long 1 and Long 2 values for all three adhesive mixtures. A comparison between the average shear strength (Long 1, Long 2, and Long 3) of the three types of manufactured plywood is presented in Table 5. These values showed that the shear strength of the plywood manufactured with UF resins modified with furan resin was higher than the reference adhesive mixture, based on UF resin modified with PF resin. 


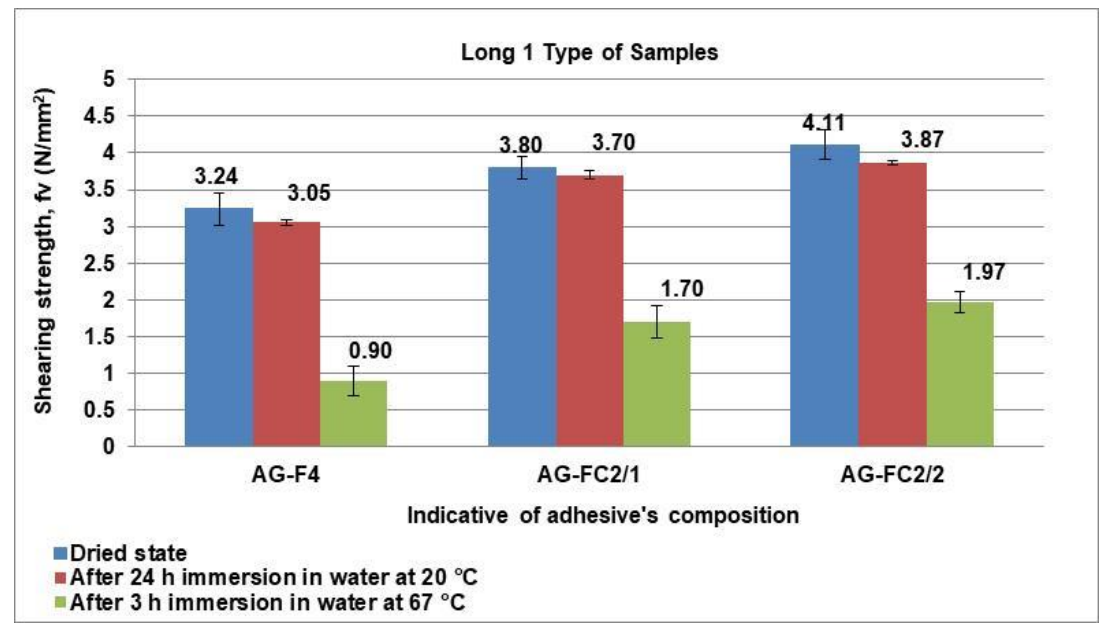

a)

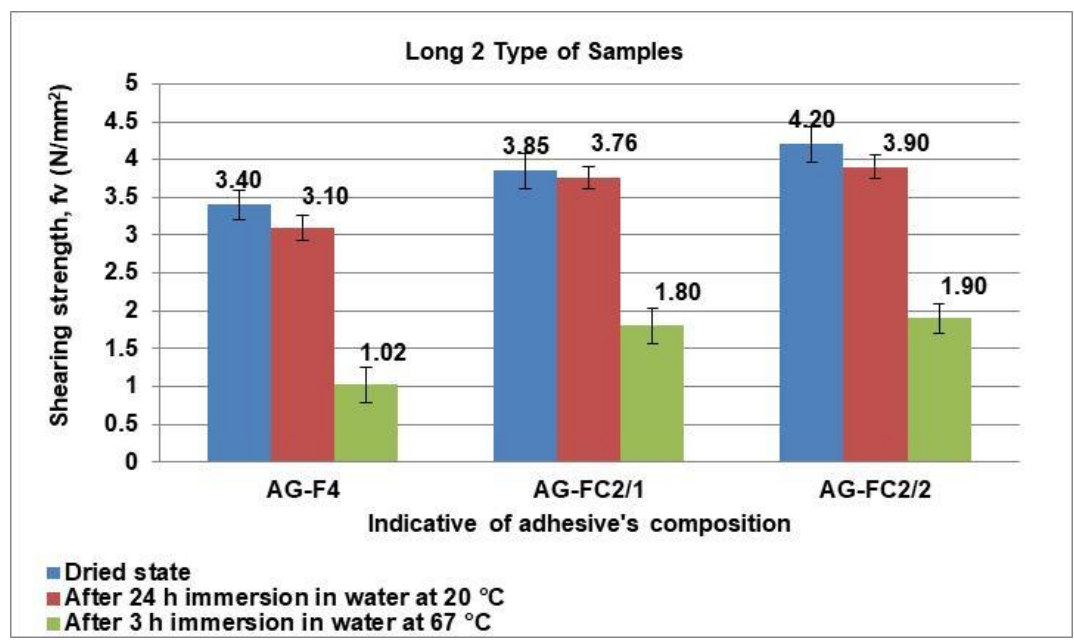

b)

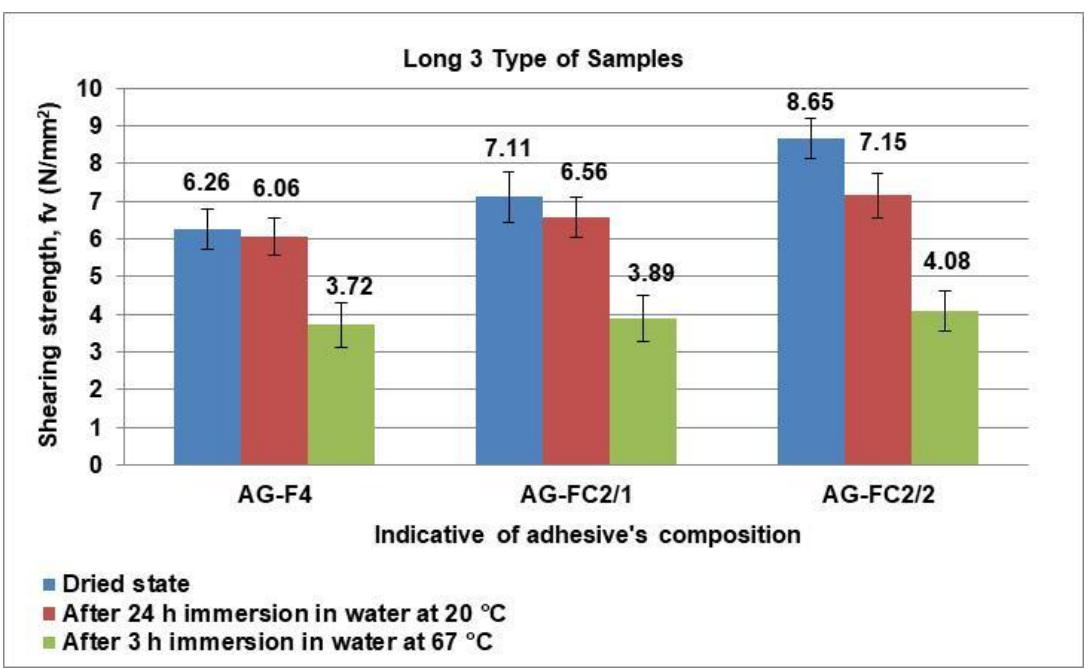

c)

Fig. 3. Average of shearing strength of Long 1 (a), Long 2 (b), and Long 3 (c) samples 
Table 5. Shear Strength Value Obtained by Average Calculation of Experimental Data for Studied Plywood

\begin{tabular}{|c|c|c|c|}
\hline \multirow{2}{*}{$\begin{array}{c}\text { Indicative of Adhesives } \\
\text { Composition }\end{array}$} & Dry State & $\begin{array}{c}\text { Shear Strength }\left(\mathrm{N} / \mathrm{mm}^{2}\right) \\
\text { Immersion in } \\
\text { Water at } 20^{\circ} \mathrm{C}\end{array}$ & $\begin{array}{c}\text { After } 3 \mathrm{~h} \\
\text { Immersion in } \\
\text { Water at } 67^{\circ} \mathrm{C}\end{array}$ \\
\cline { 2 - 4 } & 4.30 & 4.07 & 1.88 \\
\hline AG-F4 & 4.92 & 4.67 & 2.46 \\
\hline AG-FC2/1 & 5.65 & 4.97 & 2.65 \\
\hline AG-FC2/2 & \multicolumn{3}{|c}{} \\
\hline
\end{tabular}

The data presented in Table 5 show that the shear strength for the adhesive composition AG-FC2/1 increased compared to the reference AG-F4 as follows: $14.4 \%$ in dry state, $14.7 \%$ in wet state after $24 \mathrm{~h}$ immersion in water at $20{ }^{\circ} \mathrm{C}$, and with $30.8 \%$ in wet state, after $3 \mathrm{~h}$ immersion in water at $67^{\circ} \mathrm{C}$. When the addition of furan resin was increased, the shear strength was much higher than the reference sample with $31.3 \%$ in dry state, with $22.1 \%$ after $24 \mathrm{~h}$ immersion in water and with $40.9 \%$ after $3 \mathrm{~h}$ immersion in water at $67^{\circ} \mathrm{C}$.

The percentage of wood failure of the tested samples is presented in Fig. 4.

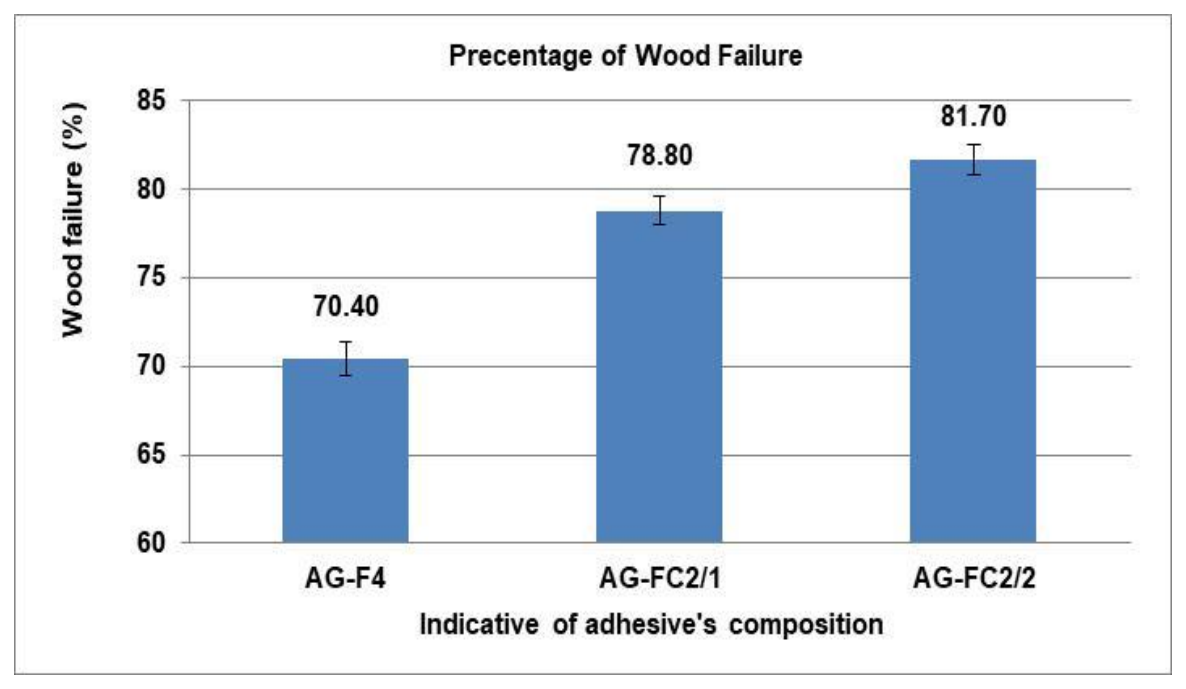

Fig. 4. Percentage of wood failure after shear strength test

In Fig. 4, the percentage of wood failure estimated as the percent of wood fibers in the breaking area is presented to highlight the good resistance of furan resin in the glued layers. For example, for the reference adhesive composition, the surface covered with wood fiber is approximately $70 \%$, while $30 \%$ was covered with adhesive film. For the adhesive compositions modified with furan resin, the clear glue film area had a smaller percentage of surface covered with wood fibers after breaking, being approximately $80 \%$ from the total glued area. According to SR EN 3141 (2005) is not compulsory to evaluate the wood failure when the shear strength is higher than $1 \mathrm{~N} / \mathrm{mm}^{2}$.

The results correlated with the requirement of SR EN 3142 (2004) regarding the bonding quality indicated that the experimental plywood panels can be classified in Class 1 (the imposed limit is a minimum shear strength of $0.2 \mathrm{~N} / \mathrm{mm}^{2}$ ). However, it can be seen 
that the addition of furan resin significantly increased the shear strength of glued joints in the obtained plywood (based on ANOVA statistical analysis, the P value was 0.001 ).

\section{Bending strength and modulus of elasticity in bending}

The results of these tests were expressed as an average of five test pieces for each type of plywood and are presented in Fig. 5 (MOR - Fig 5a and MOE - Fig. 5b) with the corresponding standard deviations.

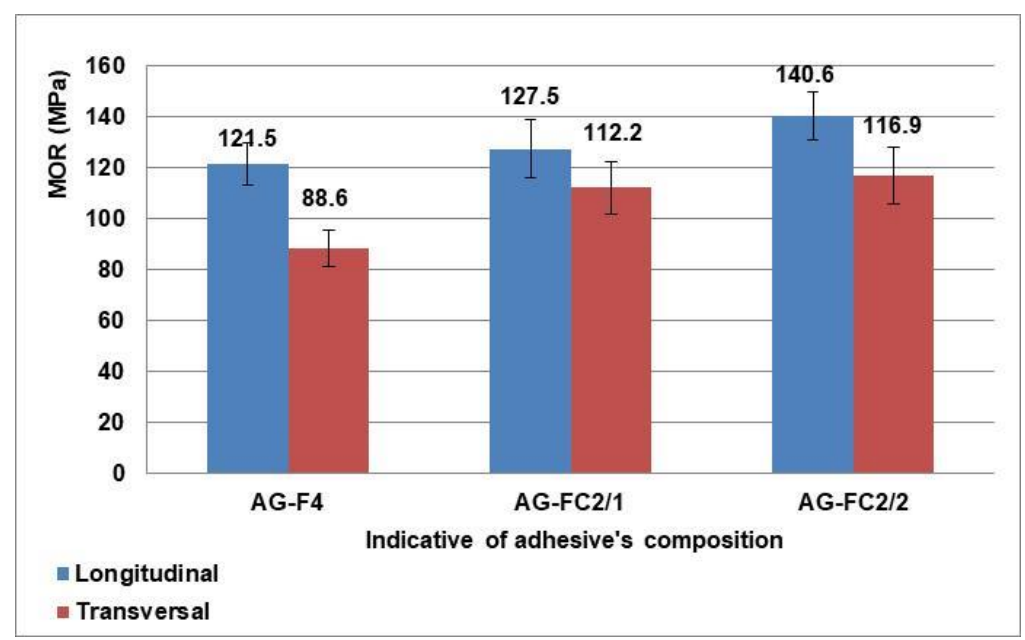

a)

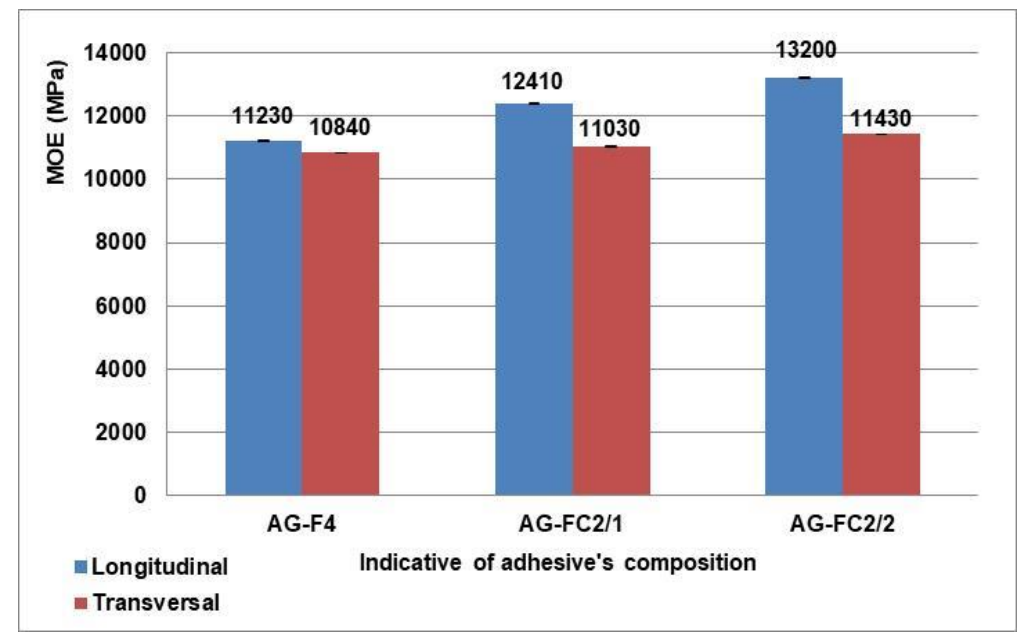

b)

Fig. 5. The bending strength (a) and the modulus of elasticity (b) registered for the manufactured plywood

The data presented in Fig. 5 show that the bending strength of plywood obtained with the adhesive composition modified with furan resin was higher than for the reference plywood. The increasing in the bending strength on the longitudinal direction was approximately $4 \%$ to $16 \%$ in the transversal direction.

Esmaili (2017) obtained some similar results performed on the particleboards glued with adhesives based on a urea-hydroxymethyl furfural-formaldehyde resin. He also mentioned the water resistance improvement of these wood-based products with the addition of furfural in adhesive synthesis. 
The modulus of elasticity in bending increased for modified plywood with approximately $10 \%$ to $17 \%$ in the longitudinal direction and $1.7 \%$ to $5.4 \%$ in the transversal direction, compared to the reference.

Therefore, the plywood made with the adhesive mixture based on ureaformaldehyde resin modified with furan resin was more rigid and more resistant to rupture.

\section{CONCLUSION}

1. The adhesive compositions based on the urea-formaldehyde resin in addition with furan resin improved the properties of plywood.

2. The cured adhesives modified with furan resins investigated by FTIR, revealed that the peak for methylene bridges is higher, being characteristic for condensation resole resins with more methylene bridges formed by curing.

3. The beech plywood for interior use made with UF adhesives modified with furan resin, showed a better resistance to water and superior mechanical properties, compared to those of similar products glued with a similar addition of phenolformaldehyde resin.

4. The manufactured plywood can be classified as Class 1, according to the requirements of bonding quality, and classified in the E1 class of formaldehyde emission.

5. The results indicated that the furan resins could be a substitute for the phenolformaldehyde resins, which are commonly employed in plywood manufacturing for improving the water resistance of plywood made with UF resins.

\section{ACKNOWLEDGMENTS}

The authors would like to honor the memory of Dr. Valeriu Petrovici, the authors' most revered colleague, who initiated and conducted this research in the field of furan resin adhesives. The authors also acknowledge the structural funds project PRO-DD (POS-CCE, O.2.2.1., ID 123, SMIS 2637, and ctr. No 11/2009) for providing the infrastructure used in this work at the CDI Institute of Transilvania University of Brasov.

\section{REFERENCES CITED}

Abdullah, U. H. B., and Pizzi, A. (2013). "Tannin-furfuryl alcohol wood panel adhesives without formaldehyde," European Journal of Wood and Wood Products 71(1), 131132. DOI: 10.1007/s00107-012-0629-4

Djiporovic-Momcilovic, M., Gavrilovic-Grmuša, I., Todorovic, T., Popovic, M., Medved, S., Popovic, J., and Hamid, F., (2018). "Evaluation of two ultrasonic methods for preparing urea-formaldehyde adhesives with nano-SiO ${ }_{2}$," Pro Ligno 14(4), 39-44. 
Dongre, P., Driscoll, M., Amidon, T., and Bujanovic, B. (2015). "Lignin-furfural based adhesives," Energies 8(8), 7897-7914. DOI: 10.3390/en8087897

Dong, Y., Yan, Y., Zhang, S., and Li, J. (2014). "Wood/polymer nanocomposites prepared by impregnation with furfuryl alcohol and nano-SiO 2, , BioResources 9(4), 6028-6040. DOI: 10.15376/biores.9.4.6028-6040

Esmaeili, N., Zohuriaan-Mehr, M. J., Mohajeri, S., Kabiri, K., and Bouhendi, H. (2017). "Hydroxymethyl furfural modified urea formaldehyde resin - Synthesis and properties," European Journal of Wood and Wood Products 75(1), 71-80. DOI: 10.1007/s00107-016-1072-8

Gosselink, R. J. A., Van Dam, J. E. G., de Jong, E., Gellerstedt, G., Scott, E. L., and Sanders, J. P. M. (2011). "Effect of periodate on lignin for wood adhesive application," Holzforschung 65(2), 155-162. DOI: 10.1515/HF.2011.025

Hao, X., and Fan, D. B. (2018). "Preparation and characterization of epoxy-crosslinked soy protein adhesive," Journal of Adhesion Science and Technology 32 (24), 26822692, DOI: 10.1080/01694243.2018.1517488

Hemmilä, V., Adamopoulos, S., Karlsson, O., and Kumar, A., (2017). "Development of sustainable bio-adhesives for engineered wood panels - A Review," RSC Adv. 7, 3860438630. DOI: $10.1039 / \mathrm{c} 7 \mathrm{ra06598a}$

Herold, N., Lenz, C., and Pfriem, A. (2014). "Changes in cell wall dimensions during the different stages of furfuryl alcohol modification," BioResources 9(3), 4756-4763. DOI: 10.15376/biores.9.3.4756-4763

Kim, M. G., Wasson, L., Burris, M., Wu, Y. M., Watt, C., and Strickland, R. C. (1998). "Furfuryl alcohol emulsion resin as cobinders for urea-formaldehyde resin bonded particleboard," Wood and Fiber Science 30(3), 223-237.

Luckeneder, P., Gavino, J., Kuchernig, R., Petutschnigg, A., and Tondi, G. (2016). "Sustainable phenolic fractions as basis for furfuryl alcohol based co-polymers and their use as wood adhesives," Polymers 8(11), 396. DOI: 10.3390/polym8110396

Niir Project Consultancy Services Board of Consultants and Engineers (2007). The Complete Book on Adhesives, Glues, and Resins Technology (with Process and Formulations) (2nd Revised Edition), Asia Pacific Business Press Inc., NIIR Project Consultancy Services, Kamla Nagar, New Delhi, India.

Pizzi, A., and Mittal, K. L. (2003). "Urea-formaldehyde adhesives," Handbook of Adhesives Technology Revised and Expanded, CRC Press, New York, NY, USA.

Pizzi, A. (2016). "Wood products and green chemistry," Annals of Forest Science 73(1), 185-203. DOI: 10.1007/s13595-014-0448-3

Ponomarev, A. A. (1960). Syntheses and Reactions of Furan Compounds, Saratov State University, Saratov, Russia.

Rivero, G., Fasce, L. A., Cere, S. M., and Manfredi, L. B. (2014). "Furan resin as replacement of phenolic protectives coatings-Structural, mechanical, and functional characterization," Progess in Organic Coatings 77, 247-256. DOI: 10.1016/j.porgcoat.2013.09.015

Schneider, S. (2002). “Multilayer pearl lustre pigment,” U.S. Patent No. 6747073.

Schultz, T. P. (1990). "Exterior plywood resin formulated from furfuryl alcohol and paraformaldehyde," Holzforschung 44(6), 467-468. DOI: 10.1515/hfsg.1990.44.6.467

SR EN 310 (1996). "Wood-based panels - Determination of modulus of elasticity in bending and of bending strength," ASRO-International Organization for Standardization, Bucharest, Romania. 
SR EN 314-1 (2005). "Plywood bonding quality - Part 1 - Test methods," ASROInternational Organization for Standardization, Bucharest, Romania.

SR EN 314-2 (2004). "Plywood bonding quality - Part 2 - Requirements," ASROInternational Organization for Standardization, Bucharest, Romania.

SR EN 322 (1996). "Wood based panels - Determination of moisture content," ASROInternational Organization for Standardization, Bucharest, Romania.

SR EN 323 (1996). "Wood based panels - Determination of density," ASROInternational Organization for Standardization, Bucharest, Romania

SR EN 324-1 (1993). "Wood-based panels - Determination of dimensions of boards Part 1 - Determination of thickness, width, and length," ASRO-International Organization for Standardization, Bucharest, Romania.

SR EN 636 (2004). "Plywood - Specifications," ASRO-International Organization for Standardization, Bucharest, Romania.

SR EN 717-2 (1995). "Wood-based panels - Determination of formaldehyde release Part 2 - Formaldehyde release by the gas analysis method," ASRO-International Organization for Standardization, Bucharest, Romania.

STAS 10913 (1977). "Plywood - Determination of water absorption," ASROInternational Organization for Standardization, Bucharest, Romania.

Tian, Q., Yuana, Y. C., Rong, M. Z., and Zhang, M. Q. (2009). “A thermally remendable epoxy resin," J. Mater. Chemistry 19, 1289-1296. DOI: 10.1039/B811938D

Varodi, A. M., Timar, M. C., and Petrovici, V. (2013). "Furan resins as potential structural adhesives for wood," Pro Ligno 9(4), 144-152.

Zeleniuc, O., Varodi, A. M., Petrovici, V., and Badescu, A.-M. L. (2010). "Mechanical properties of wooden laminated structures glued with a furan resin based adhesive," in: Proceedings of the International Conference on Urban Sustainability, Cultural Sustainability, Green Development Green Structures, and Clean Cars, Uscudar, Malta, pp. 143-147.

Zhang, J., Chen, H., Pizzi, A., Li, Y., Gao, Q., and Li, J. (2014). "Characterization and application of urea-formaldehyde furfural co-condensed resins as wood adhesives," BioResources 9(4), 6267-6276. DOI: 10.15376/biores.9.4.6267-6276

Article submitted: July 25, 2017; Peer review completed: December 16, 2018; Revised version received: February 1, 2019, Accepted: February 2, 2019; Published: February 13, 2019.

DOI: 10.15376/biores.14.2.2727-2739 